
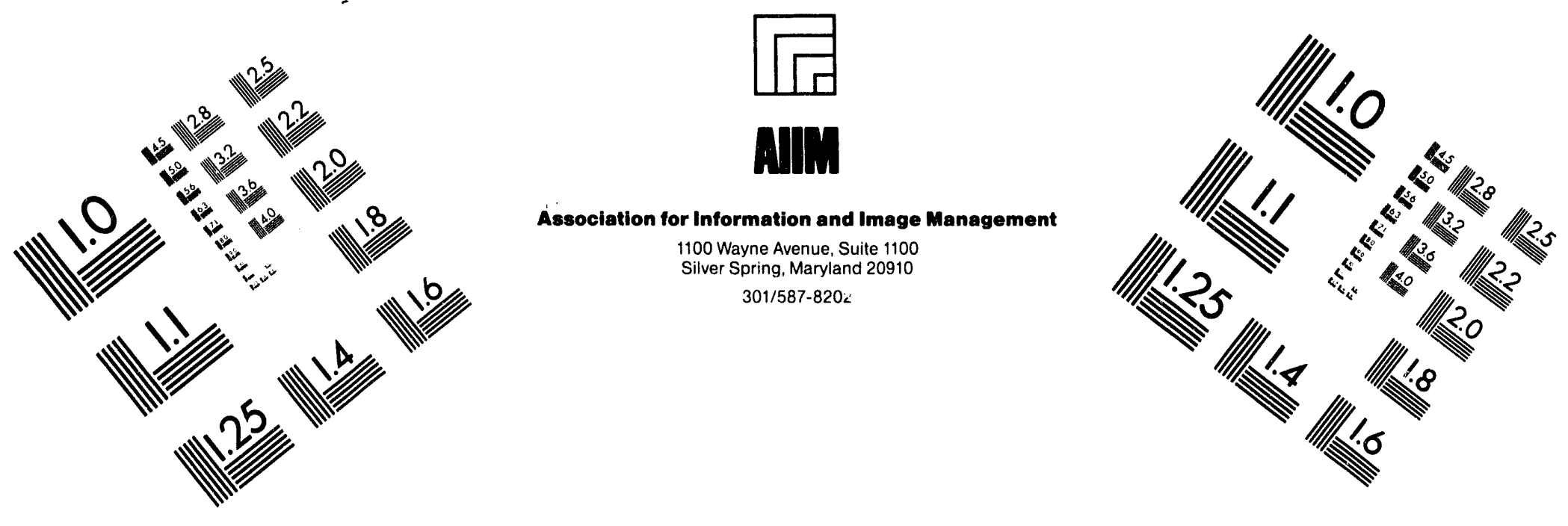

\title{
Centimeter
}

$\begin{array}{llllllllllllllll}1 & 2 & 3 & 4 & 5 & 6 & 7 & 8 & 9 & 10 & 11 & 12 & 13 & 14 & 15 & \mathrm{~mm}\end{array}$ $\mid$ Inches
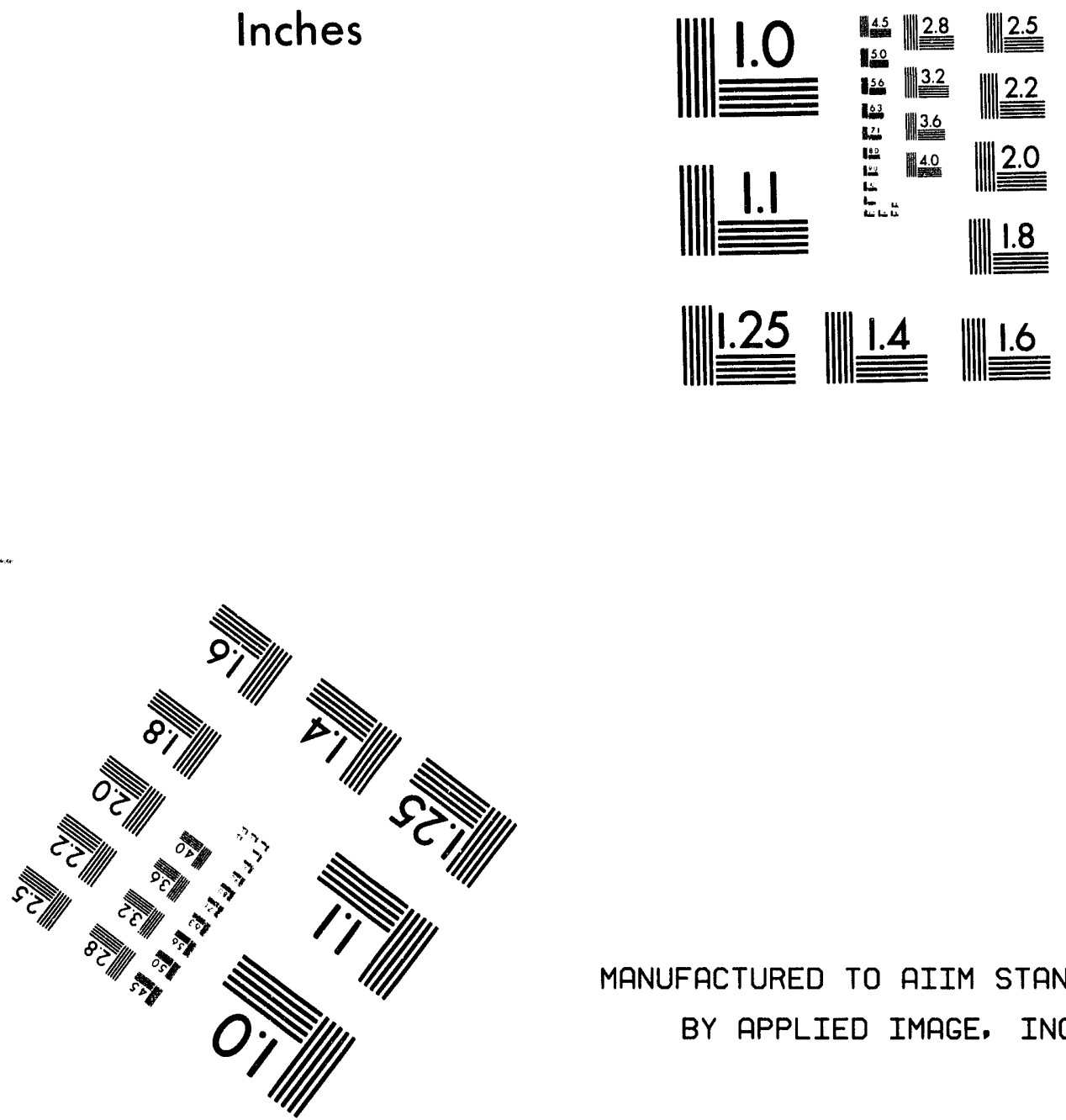

MANUFACTURED TO AIIM STANDARDS

BY APPLIED IMAGE, INC.

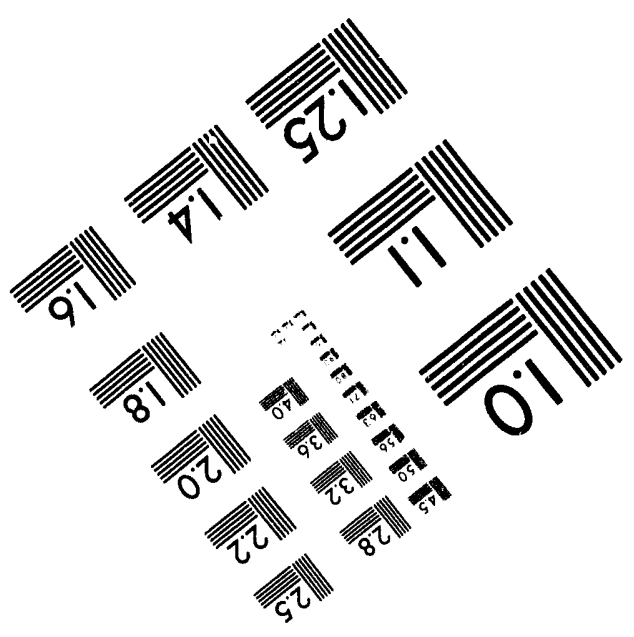



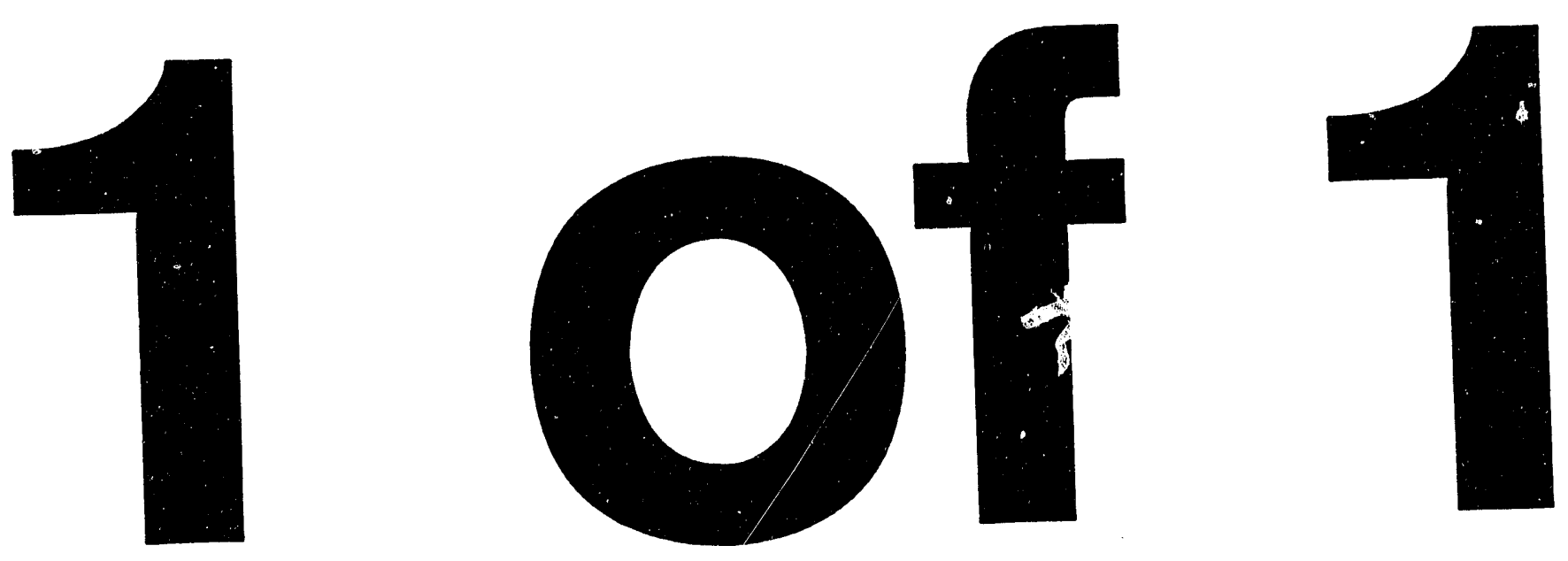


\title{
DISCLAIMER
}

This report was prepared as an account of work sponsored by an agency of the United States Government. Neither the United States Government nor any agency thereof, nor any of their employees, makes any warranty, express or implied, or assumes any legal liability or responsibility for the accuracy, completeness, or usefulness of any information, apparatus, product, or process disclosed, or represents that its use would not infringe privately owned rights. Reference herein to any specific commercial product, process, or service by trade name, trademark, manufacturer, or otherwise does not necessarily constitute or imply its endorsement, recommendation, or favoring by the United States Government or any agency thereof. The views and opinions of authors expressed herein do not necessarily state or reflect those of the United States Government or any agency thereof.

\section{The Functions of Tryptophan Residues in Membrane Proteins*}

M. Schiffer, C.-H. Chang, and F. J. Stevens

\author{
Key words: Membrane proteins, membrane insertion, hydrogen \\ bonding, tryphophan function, photosynthetic reaction \\ center
}

*This work is supported by the U.S. Department of Energy, Office of Health and Environmental Research, under Contract No. W-31-109ENG-38. 


\section{Abstract}

Membrane proteins in general have a significantly higher Trp

content than do soluble proteins. This is especially true for the $M$ and $L$ subunits of the photosynthetic reaction center from purple bacteria. The Trp residues are located mostly in the segments that connect the transmembrane helices. Further, they are concentrated at the periplasmic side of the complex. Within the protein subunits, many form hydrogen bonds with carbonyl oxygens of the main chain, thereby stabilizing the protein. On the surface of the molecule, they are correctly positioned to form hydrogen bonds with the lipid head groups while their hydrophobic rings are immersed in the lipid part of the bilayer. We suggest that Trp residues are involved in the translocation of protein through the membrane and that following translocation, Trp residues serve as anchors on the periplasmic side of the membrane. 
Proteins that span membranes or are anchored in membranes play critical roles in cell regulation, molecular transport, and energy transduction. The most detailed information describing threedimensional structural properties of membrane-spanning proteins is provided by $x$-ray diffraction study of the photosynthetic reaction center (RC) from two bacterial species, Rhodopseudomonas viridis and Rhodobacter sphaeroides (Deisenhofer and Michel, 1989; Feher et al., 1989; Chang et al., 1991). The RCs have three membranespanning subunits designated $L, M$, and $H$. The bulk of the $H$ subunit, which has only one membrane-spanning helix, is located in the cytoplasm. The $I$ and $M$ subunits each have five transmembrane helical segments and are mainly located within the membrane. Tile Trp contents of the $L$ and $M$ subunits are higher than those of soluble proteins. Further, we and Deisenhofer and Michel (1989) have noticed an unusual asymmetric distribution of Trp residues in the $I$ and $M$ subunits: they are located mostly on the periplasmic side of the complex. This Trp distribution can also be found in 
the structure of bacteriorhodopsin (Henderson et al., 1990) and in

a larger data set studied by von Heijne (1986).

von Heijne analyzed the distribution of amino acid residues in bacterial membrane proteins, comparing the amino acid composition of cytoplasmic loops, periplasmic loops, and transmembrane helices. The data base consisted of membrane proteins and soluble proteins. Trp accounts for approximately $3.3 \%$ of the residues in membrane proteins but only 1.28 of the residues in soluble proteins. The Trp content in the transmembrane helices and connecting loops of the membrane proteins is comparable. This contrasts with the distribution of other hydrophobic amino acids, (Phe, Ile, Leu, Met, and Vall. These residues represent $56 \%$ of the residues of the transmembrane helices and $26 \%$ of the connecting loops in membrane proteins. The latter value is comparable to a $28 \%$ contribution of these residues in soluble proteins.

The average Trp content of the $L$ and $M$ subunits of three reaction centers (Michel et al., 1986) is 5.8\%, almost twice as high as in the von Heijne data set. Trp residues make up $5.2 \%$ of 
the tiansmembrane helical segment and $6.4 \%$ of the residues in the connecting segments. As was found in the other membrane proteins, hydrophobic amino acids represent almost half (43\%) of the residues in the transmembrane helices and less than one-third (27\%) of the connecting segments in the reaction center $I$ and $M$ chains. These observations suggest that another property of the Trp residue, in addition to its hydrophobic character, is important for its function in membrane proteins.

The Trp residue has a large indole (benzopyrrole) side chain that consists of two fused aromatic rings. Because of its aromatic character, it is capable of $\pi-\pi$ interactions and of weakly polar interactions (Burley and Petsko, 1988). Trp is a very hydrophobic residue, but it is also capable of hydrogen bonding. The two functional groups of this bifunctional side chain are separated from each other (Eig. 1).

In well refined structures, of soluble proteins, analyzed by Baker and Hubbard (1984), over 85\% of the Trp residues were 
observed to form hydrogen bonds, and 308 of the hydrogen bonds were formed with main chain carbonyls.

In the RC, we found a large fraction of the Trp residues near the periplasmic side of the complex at a level that would be near the head groups of the lipid molecules (Figure 2). Half of these residues (mostly conserved in Rps. viridis and $\underline{R b}$. Sphaeroides) form hydrogen bonds with the carbonyl oxygen of a distant chain segment, while their hydrophobic ring is buried in the hydrophobic part of the protein molecule (Eigure 3). The remaining Trp side chains are on the surface of the complex in a position in which they could form hydrogen bonds with the head group of the lipid while their hydrophobic portion could be buried in the hydrophobic portion of the lipid bilayer (Eigure 3).

The localization of Trp on the surface of the RC complex in a position that would be near the polar head groups of the lipid bilayer is in agreement with results obtained by insertion of Trpcontaining peptides into model membranes by Jacobs and white (1986, 1989). In their neutron diffraction study, the insertion of a 
small Trp-containing peptide into a model membrane resulted in the localization of $\operatorname{Trp}$ in the headgroup region of the membrane. A change in the fluorescence properties of the Trp following insertion of the peptide indicated that the side chain was close to or partially immersed in the hydrocarbon region of the bilayer. One of the most striking features of the RC structure is the clustering $\operatorname{Trp}$ residues on the periplasmic side of the complex. There are one or more Trp residues in each periplasmic segment, either in the loop region or on the nearby transmembrane helical segment. The intrinsic preference of the Trp for an interfacial environment does not explain this anisotropic distribution between the periplasmic and cytoplasmic side of the RC molecule and the analogous twofold larger Trp content of periplasmic loops over cytoplasmic loops in the von Heijne data set. We suggest that Trp, by its lipophilic nature, facilitates the translocation of the periplasmic portion of the protein through the membrane. Once the chain segment is across the membrane, the hydrogen-bonding property 
of the Trp helps to anchor the chain segment on the periplasmic side.

In addition to Trp residue, Tyr, Arg, and Lys are bifunctional amino acid residues that have hydrophobic sections and can form hydrogen bonds. The positively charged Lys and Arg residues are predominantly found in cytoplasmic loops. An anchor function for these residues on the cytoplasmic side of the membrane was suggested by von Heinje (1986) and by von Heinje and Manoil (1990). Tyr residues occur in loops on both sides of the membrane; in the $R C$, there are more on the periplasmic side of the complex. The Tyr residue, like Trp, is a hydrophobic aromatic residise and one that can also form hydrogen bonds, but the spatial distribution of polar and hydrophobic portions of the Tyr and Trp residues is different. In the $\mathrm{RC}$, the Tyr residues that are near the periplasmic side of the complex have their hydroxy group point toward the periplasm.

In proteins that have several transmembrane helical segments, Trp can act as the "needle" to pull two helices across the 
membrane, with Arg and Lys providing the "stays" on the cytoplasmic side of the membrane in a protein insertion model similar to that described by Engelman and Steitz (1981) and by Jacobs and White (1989). In accordance with this model, in bacteriorhodopsin (Henderson et al., 1990) and also in the predicted structure of the structurally related muscarinic receptor (Hulme et al., 1990), each cytoplasmic segment has at least one Arg or Lys residue and each extracellular segment has at least one Trp or Tyr residue either in the loop region or at the beginning or end of the transmembrane helical segment.

The bifunctional qualities of Trp make it an important structural component for membrane proteins. One function of $\operatorname{Trp}$ residues in membrane proteins appears to be to link distant chain segments or to bridge subunits through hydrogen bonding with carbonyl oxygens or sidechain functional groups. Trp side chains appear to contribute significantly to the stability of RC position and orientation in the membrane by, potentially, forming hydrogen bonds with the lipid head-group while the hydrophobic part of the 
residue is buried in the hydrophobic portion of the lipid bilayer. The asymmetrical distribution of Trp residues, which favors the periplasmic side of the complex, might help the translocation of these proteins through the membrane. The distribution of Trp residues is the opposite of that described for the negatively charged Arg and Lys residues (von Heijne, 1986; von Heijne and Manoil, 1990), for which an anchor function at the cytoplasmic side of the membrane was suggested.

Acknowledgment

We thank Celia Schiffer for useful discussions.

\section{References}

Baker, E. \& Hubbard, R. (1984). Hydrogen bonding in globular proteins. Prog. Biophys. Molec. Biol. 44, 97-179. 
Burley, S. \& Petsko, G. (1988). Weakly polar interactions in proteins. Adv. Prot. Chem. 39, 125-189.

Chang, C.-H., El-Kabbani, O., Tiede, D., Norris, J. \& Schiffer, M. (1991). The structure of the membrane-bound protein photosynthetic reaction center from Rhodobacter sphaeroides. Biochemistry (in press).

Deisenhofer, J. \& Michel, H. (1989). The photosynthetic reaction centre from the purple bacterium Rhodopseudomonas viridis. EMBO J. 8, 2149-2169.

Engelman, D. M. \& Steitz, T. A. (1981). The spontaneous insertion of proteins into and across membranes: the helical hairpin hypothesis. Cell 23, 411-422.

Feher, G., Allen, J. P., Okamura, M. Y. \& Rees, D. C. (1989). Structure and function of bacterial photosynthetic reaction centres. Nature 339, 111-116. 
Henderson, R., Baldwin, J. M., Ceska, T. A., Zemlin, F., Beckmann, E. \& Downing, K. H. (1990). Model for the structure of bacteriorhodopsin based on high-resolution electron cryomicroscopy. J. Mol. Biol, 213, 899-929.

Hulme, E. C., Birdsall, N. J. M. \& Buckley, N. J. (1990) . Muscarinic receptor subtypes. Annu. Rev. Pharmacol. Toxicol. $30,633-673$

Jacobs, R. \& Wite, S. (1986). Mixtures of a series of homologous hydrophobic peptides with lipid bilayers: a simple model system for examining the protein-lipid interface. Biochemistry 25, 2605-2612.

Jacobs, R. \& Wite, S. (1989). The nature of the hydrophobic binding of small peptides at the bilayer interface: implications for the insertion of transbilayer helices. Biochemistry 28, 3421-3437. 
Michel, H., Weyer, K., Gruenberg, H., Dunger, I., Oesterhelt, D. \& Lottspeich, F. (1986). The 'light' and 'medium' subunits of the photosynthetic reaction centre from Rhodopseudomonas viridis: isolation of the genes, nucleotide and amino acid sequence. EMBO J. 5, 1149-1158.

von Heijne, G. (1986). The distribution of positively charged residues in bacterial inner membrane proteins correlates with the trans-membrane topology. EMBO J. 5, 3021-3027. von Heijne, G. \& Manoil, C. (1990). Membrane proteins: from sequence to structure. Protein Engineering 4, 109-112.

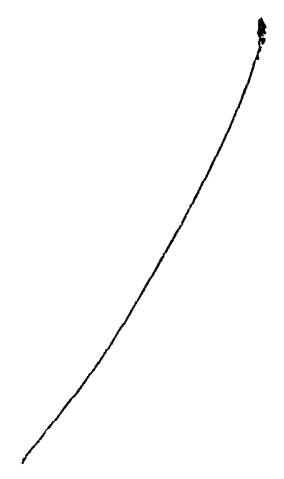




\section{Eigure Legends}

Eigure 1. The geometry of hydrogen bonding by a Trp residue observed in RC is illustrated. The hydrophobic benzene ring is spatially separated from the hydrogen-bonding part of the residue. This property of $\operatorname{Trp}$ allows a hydrophobic interaction to take place separated from the hydrogen bond and makes it an important residue in stabilizing membrane proteins.

Figure 2. The distribution of Trp residues in the RC derived from Rb. sphaeroides is shown with the protein backbone and by themselves. The periplasmic side of the complex is near the top of the figure; most of the Trp residues are located in this part of the molecule.

Eigure 3. Stereo picture of the periplasmic segment of the complex as viewed from the cytoplasmic side. The orientations of the Trp residues are shown. The Trp residues on the surface of the complex are in a position to hydrogen bond with the lipid head group while their hydrophobic 
benzene moeity can interact with the alkyl chains of the lipid. 


$$
x^{\prime}
$$



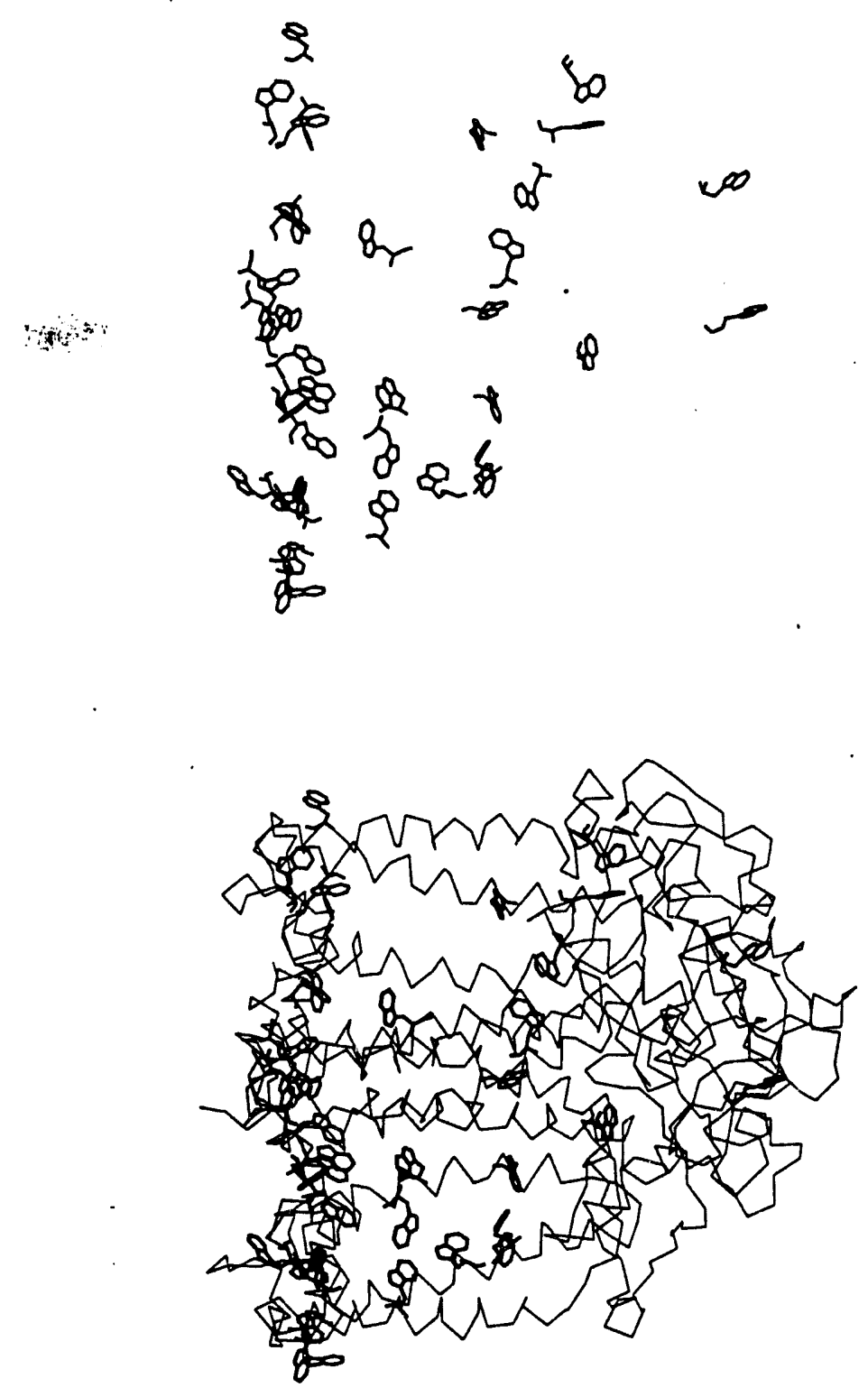

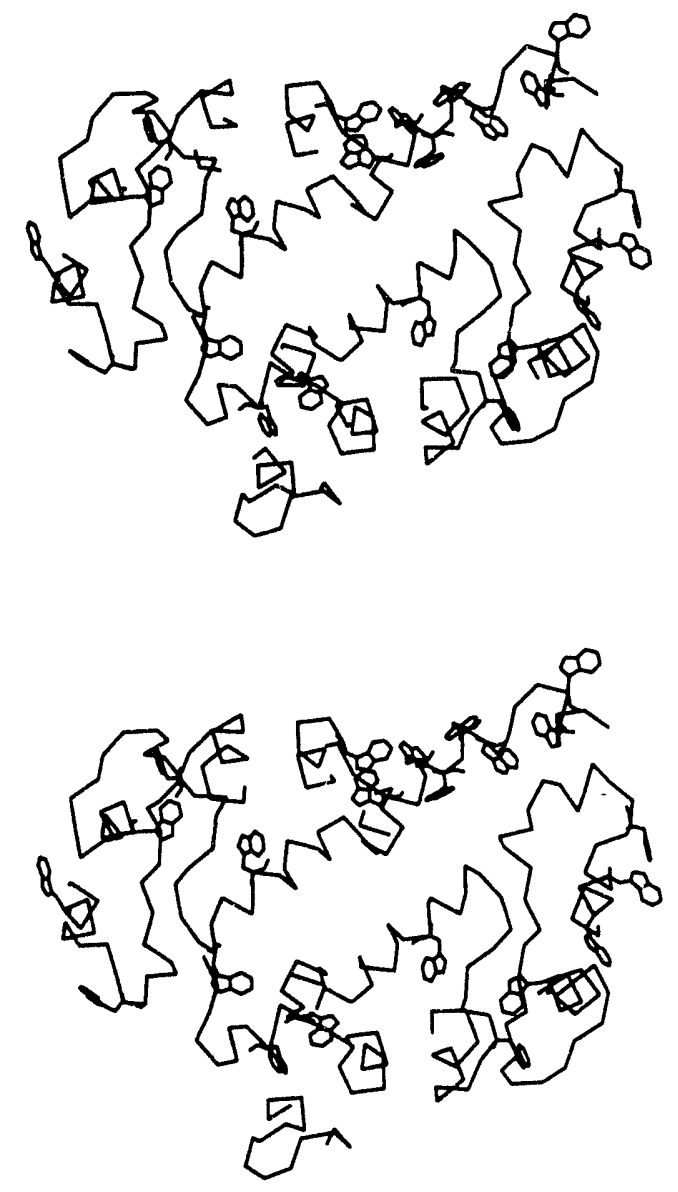

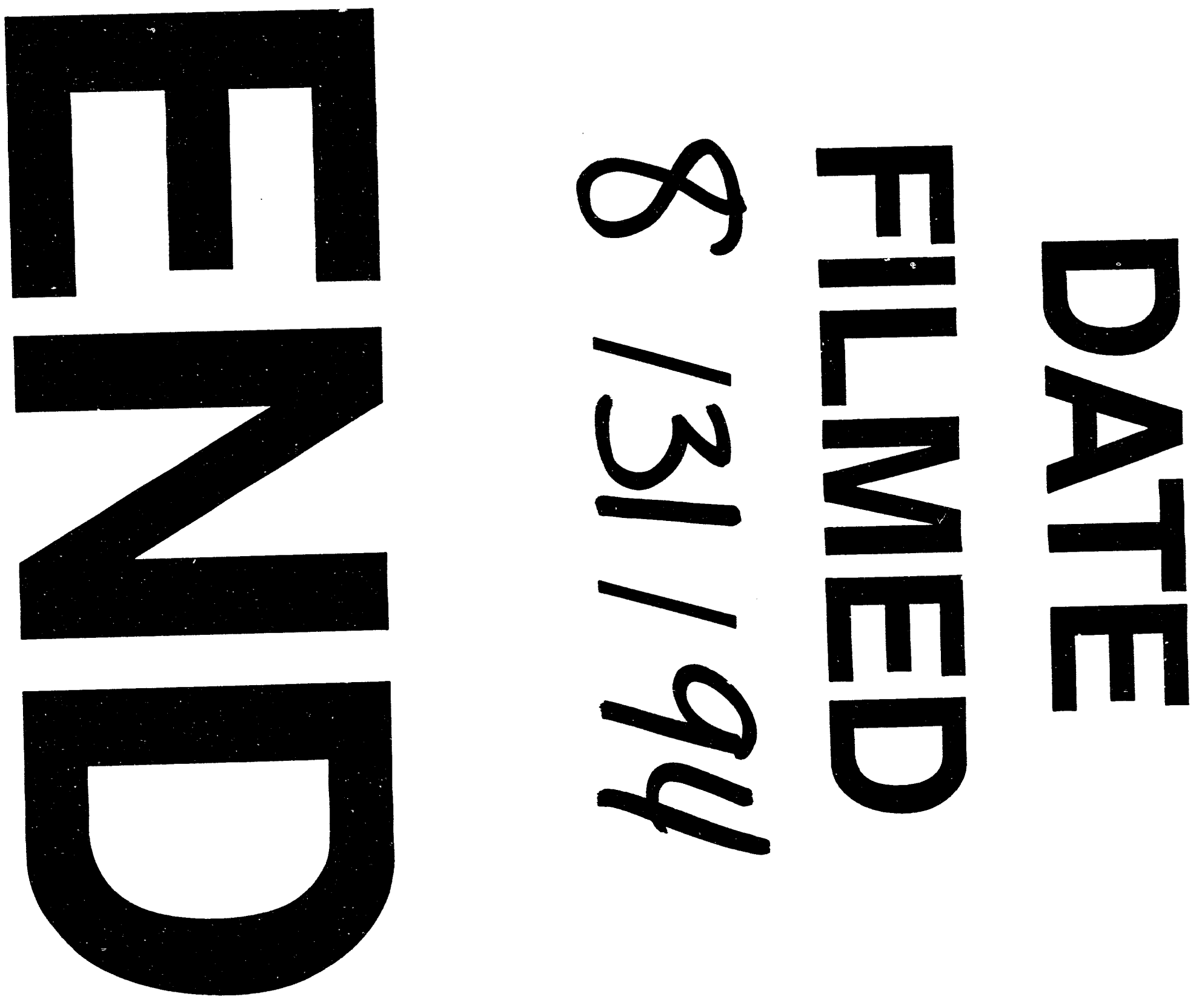


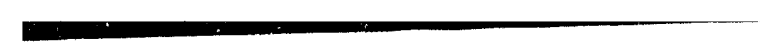

